\title{
Preparation of Morphine Derivatives Using Ionic Liquids
}

\author{
Sureshbabu Jayachandra, Madhuresh Kumar Sethi*, Sanjay Mahajan, Kunwar Sanjeev Singh, Bhairaiah Mara and \\ Purbita Chakraborty
}

Mylan Laboratories Ltd. ANRICH Industrial Estate, India

Received: 帮 May 25, 2018; Published: 監 June 11, 2018

*Corresponding author: Madhuresh Kumar Sethi, R and D, Mylan Laboratories Ltd, A ANRICH Industrial Estate, Bollaram, Sangareddy, Telangana, India, Email: madhuresh.sethi@mylan.in

\begin{abstract}
Dextromethorphan, an anti tussive drug belongs to the morphinan family, and is mostly available in the market as a combination therapy. Most of the reported preparation procedures involve the use of racemic starting materials that give lower yields. (S)- Octa base is one of the key starting raw materials used in our process and this easy, convenient and eco-friendly preparation (single step) is reported in this manuscript. This drug, Dextromethorphan is produced in large volumes annually ( $>150$ tons/year). Most reported synthetic procedures make use of huge amounts of volatile organic solvents which are hazardous for environment. This will be a major issue in the near future. To overcome this problem, we have tried using Ionic liquid as a solvent in the preparation and successfully arrived at best results, thereby decreasing the use of organic volatile solvents.
\end{abstract}

Keywords: Dextromethorphan; Morphine derivatives; Alkaloids; Formylation; Ionic liquid

\section{Introduction}

Dextromethorphan, a drug of the morphinan family, is having tranquilizing, dissociative, and restorative properties (especially at higher doses). It is a cough suppressant (ANTI-TUSSIVE) in several over-the-counter cold and cough medicines including generic labels and store brands, Benylin, Mucinex, Camydex 20 tablets, Robitussin, NyQuil, Vicks, Delsym, TheraFlu, Cheracol D, and others. It has also found plentiful other uses in medication, extending from analgesic effect to psychological submissions useful in the treatment of addiction. It is sold in syrup, capsule, and lozenge forms. In its unadulterated form, Dextromethorphan ensues as a white powder. Currently, Dextromethorphan is not registered in the Schedules of the United Nations 1961 Convention on Narcotic Drug [1].

Dextromethorphan is the dextrorotatory enantiomer of levomethorphan, which is the methyl ether of levorphanol, both opioid analgesics. It's IUPAC name is (+)-3-methoxy-17-methyl- $9 \alpha$, $13 \alpha, 14 \alpha$-morphinan. It occurs as an odorless, opalescent white powder. It is freely soluble in chloroform and insoluble in water; the hydro bromide salt is water-soluble up to $1.5 \mathrm{~g} / 100 \mathrm{~mL}$ at 25 ${ }^{\circ} \mathrm{C}$. It is usually accessible as the monohydrated hydro bromide salt. However, some newer extended-release formulations contain
Dextromethorphan bound to an ion-exchange resin based on polystyrene sulfonic acid (Picture 1).

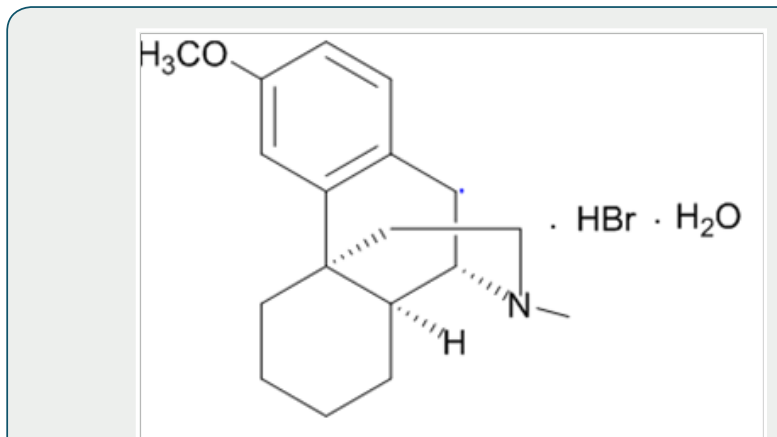

Picture 1: Chemical structure of Dextromethorphan Hydro bromide.

\section{Mechanism of Action}

Dextromethorphan is a synthetic compound and acts as a dissociative anesthetic when taken in higher doses. Its mechanism of action is via multiple effects, plus actions as a nonselective serotonin reuptake inhibitor and a sigma-1 receptor agonist [2]. Dextromethorphan and its major metabolite, Dextrorphan, also act as NMDA receptor antagonist at high doses, which produces 
effects similar to other dissociative anesthetics such as ketamine and phencyclidine [3]. The metabolic pathway continues from dextrorphan to 3-methoxymorphinan to 3-hydroxymorphinan (Figure 1) [4].

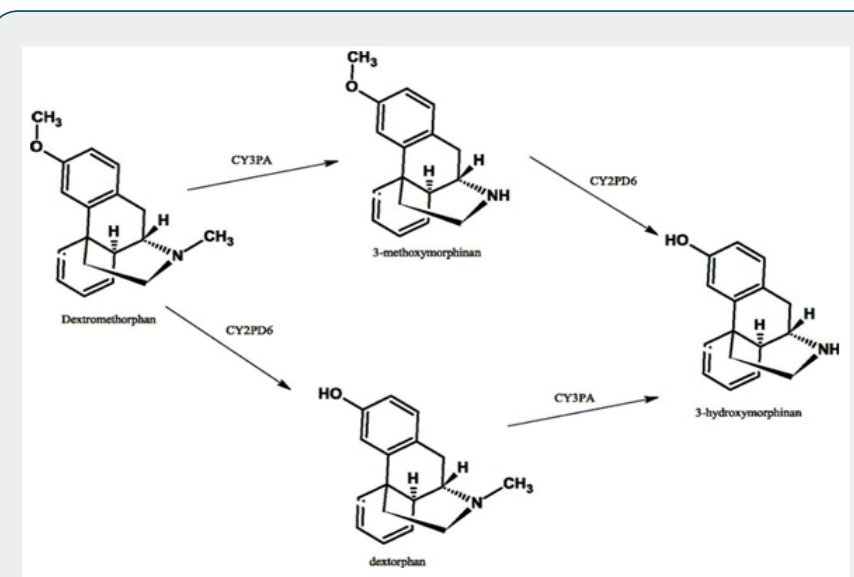

Figure 1: Explains the metabolic pathway of the drug Dextromethorphan.

In one of the reported processes for the preparation of morphinan alkaloids, racemic hydroxy $\mathrm{N}$ - methyl morphinan is used as a starting material, an optically inactive isomer and is treated with tartaric acid for resolution to obtain selective one isomer (+) of morphinan. (PATENT- US2676177 (Roche, 1954, CHprior.1949)) (Scheme 1).

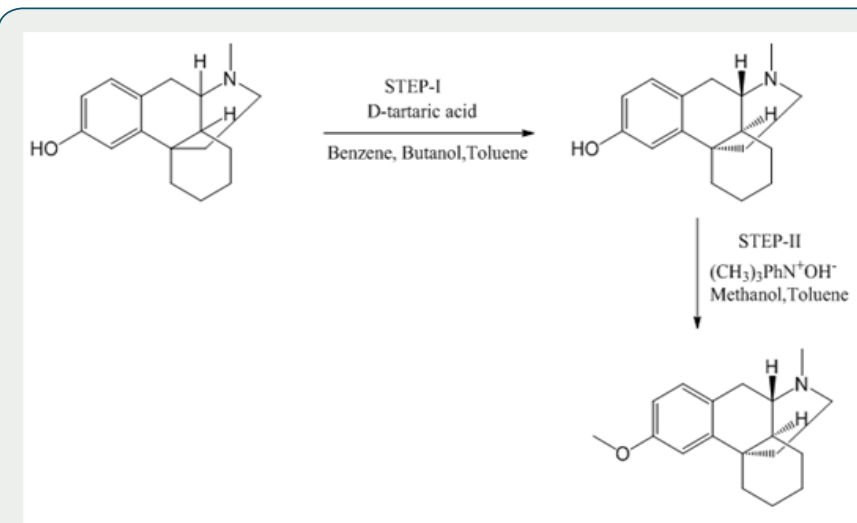

DEXTROMETHORPHAN

Scheme 1: This scheme explains the reported procedure that uses a racemic hydroxy $\mathrm{N}$ - methyl morphinan as a starting material along with the use of solvents.

In a similar procedure reported in PATENT- CN102977021 A, Method for preparation of Dextromethorphan hydro bromide By Cui, Dapeng et al From Faming Zhuanli Shenqing, 102977021, 20 Mar 2013, Raney Nickel as a reducing agent is replaced by KBH4, thus, reducing the cost. Also, resolution is done with R-ibuprofen for the first time. Another advantage is the use of $\mathrm{AlCl} 3$ is adopted to replace $\mathrm{H} 3 \mathrm{PO} 4$ to cyclize. Overall, it is a low cost, moderate reaction conditions, easy in operation and suitable for industrial production (Scheme 2).

Further, in the search for better preparation methods, which is easier, lesser preparation steps, cost effective, and also using chemicals that are easy to handle and can provide higher yields as well as purity, it has been found that the critical step of Grewe's cyclization is reported in a paper titled, 'A Novel synthesis of substituted 1-benzyloctahydroisoquinolines by acid-catalyzed cyclization of $\mathrm{N}$-[2-(Cyclohex-1-enyl]-N-styryl formamides' [5] (Scheme 3).

$$
\begin{aligned}
& \text { O }
\end{aligned}
$$

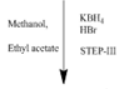

$$
\begin{aligned}
& \text { OOS }
\end{aligned}
$$

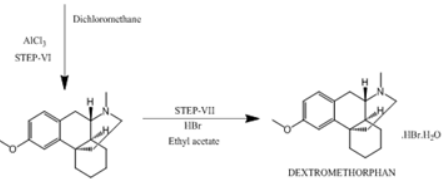

Scheme 2: Explains another reported procedure, where alternate reagents like $\mathrm{KBH}_{4}$, R-ibuprofen and $\mathrm{AlCl}_{3}$ have been used to refine the existing method of preparation of Dextromethorphan.

$$
\begin{aligned}
& \text { OYOM }
\end{aligned}
$$

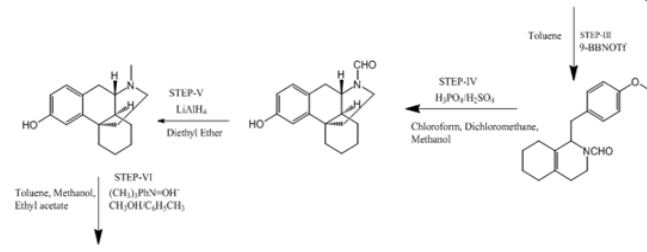

$$
\begin{aligned}
& \text { Dеттоветновнин }
\end{aligned}
$$

Scheme 3: Explains a reported procedure involving the preparation of Dextromethorphan that involves Grewe`s cyclization.

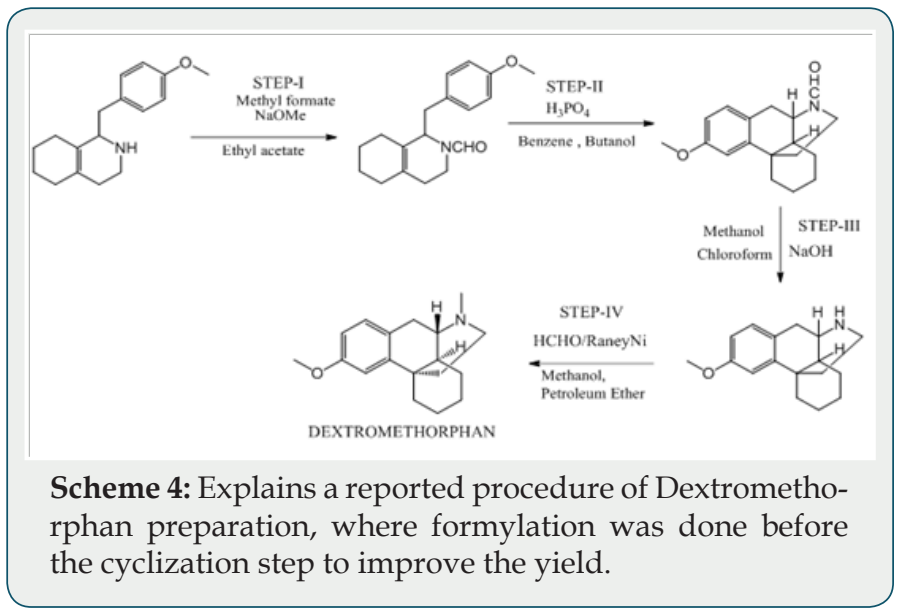

According to this paper, no cyclization of enamide was observed with Lewis acid catalyst (AlCl3, AlEtCl2, TiCl4), Two 
equivalents of BF3-Et2O was used, and complete conversion was observed. In all cyclization reactions, a side product is formed that is more polar than the octa hydroisoquinolines and $\mathrm{N}$-formyl octa hydroisoquinolines synthesized from $\mathrm{N}$-formyl2-phenylethylamines and benzaldehyde. Also, reduction of $\mathrm{N}$-formaldehyde to $\mathrm{N}$-methylated was done using LiAlH4. While going through literature, it was found that formylation before cyclisation avoids ether cleavage as a side reaction and higher yields were obtained than without $\mathrm{N}$-substitution or $\mathrm{N}$-methylation. In this patent, purification/resolution was done using the formation of Brucine salt (US3634429 (Jan 11, 1972) Morphinan derivatives and preparation there of (Scheme 4).

\section{Experimental and Results}

All the above-mentioned processes involve the use of solvents. So, in the existent investigation, an endeavor is explored to develop an alternate process wherein use of solvents can be avoided in the synthesis of Dextromethorphan (Scheme 5).

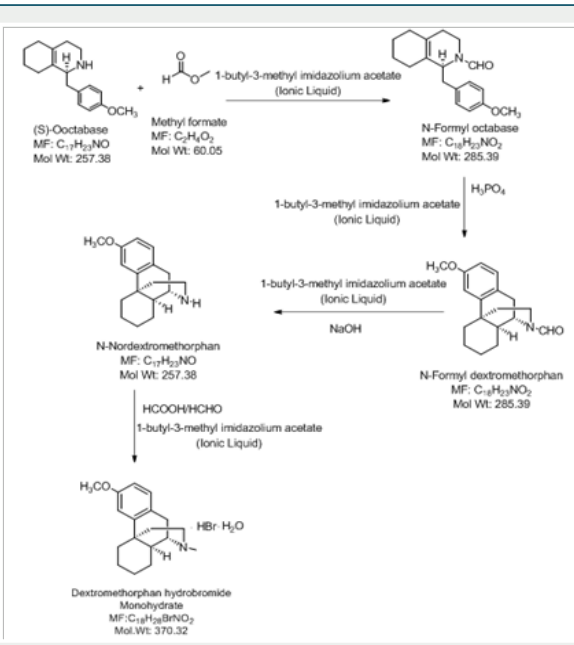

Scheme 5: Explains a greener preparation of Dextromethorphan using an Ionic Liquid.

\section{Preparation of Dextromethorphan Hydrobromide using 1-butyl-3-methyl imidazolium acetate (Ionic liquid) as a solvent}

\section{I-step:}

a) Stage-IA: In a flask, charge 1-butyl-3-methyl imidazolium acetate under nitrogen atmosphere. Charge (S)-Octa base under nitrogen atmosphere. Cool if required under nitrogen atmosphere. Charge Sodium methoxide solution in methanol under nitrogen atmosphere. Charge Methyl formate. Raise the temperature of the reaction mass to little reflux by using hot water not more than $55^{\circ} \mathrm{C}$. Stir and maintain the reaction mass till reaction complies $(2$ hours). Concentrate the reaction mass $\mathrm{u} / \mathrm{v}$ (Capacity of vacuum pump should be $>700 \mathrm{~mm} / \mathrm{Hg}$ ) till almost no solvent distills. To the concentrated reaction mass, charge toluene under nitrogen atmosphere and water extraction is done. The extracted toluene layer was concentrated to give N-Formyl octa base and is used as such. $m / z(M+H+)-286$

NMR chemical shift values tabulated below (Table 1) and (Picture 2).

Table 1: s- singlet, m-multiplet, br-broad.

\begin{tabular}{|c|c|c|c|c|c|}
\hline Position & ${ }^{1} \mathbf{H}$ & $\mathrm{d}(\mathbf{p p m})$ & Multiplicity & ${ }^{13} \mathbf{C}$ & DEPT \\
\hline 1 & $2 \mathrm{H}$ & $1.60-2.24$ & $\mathrm{~m}$ & 29.43 & $\mathrm{CH}_{2}$ \\
\hline 2 & $2 \mathrm{H}$ & $1.60-2.24$ & $\mathrm{~m}$ & 22.39 & $\mathrm{CH}_{2}$ \\
\hline 3 & $2 \mathrm{H}$ & $1.60-2.24$ & $\mathrm{~m}$ & 22.51 & $\mathrm{CH}_{2}$ \\
\hline 4 & $2 \mathrm{H}$ & $1.60-2.24$ & $\mathrm{~m}$ & 26.91 & $\mathrm{CH}_{2}$ \\
\hline 5 & - & - & - & 130.15 & - \\
\hline 6 & $1 \mathrm{H}$ & $4.07-4.13$ & $\mathrm{~m}$ & 54.69 & $\mathrm{CH}$ \\
\hline $7 \mathrm{Ha}$ & $1 \mathrm{H}$ & $2.85-3.09$ & $\mathrm{~m}$ & 32.39 & $\mathrm{CH}_{2}$ \\
\hline $7 \mathrm{Hb}$ & $1 \mathrm{~h}$ & $2.78-3.82$ & $\mathrm{~m}$ & & \\
\hline 8 & $2 \mathrm{H}$ & $1.60-2.24$ & $\mathrm{~m}$ & 29.15 & $\mathrm{CH}_{2}$ \\
\hline 9 & - & - & - & 127.49 & - \\
\hline $10 \mathrm{Ha}$ & $1 \mathrm{H}$ & $2.58-2.74$ & $\mathrm{~m}$ & 36.66 & $\mathrm{CH}_{2}$ \\
\hline $10 \mathrm{Hb}$ & $1 \mathrm{H}$ & $2.85-3.09$ & $\mathrm{~m}$ & & \\
\hline 11 & $3 \mathrm{H}$ & 3.71 & $\mathrm{~s}$ & 54.74 & $\mathrm{CH}$ \\
\hline 12 & - & - & - & 128.38 & - \\
\hline $13,13^{\prime}$ & $2 \mathrm{H}$ & $7.03-7.08$ & $\mathrm{~m}$ & 130.21 & $\mathrm{CH}$ \\
\hline 14,14 & $2 \mathrm{H}$ & $6.77-6.86$ & $\mathrm{~m}$ & 113.56 & $\mathrm{CH}$ \\
\hline 15 & - & - & - & 157.78 & - \\
\hline 16 & $1 \mathrm{H}$ & 7.34 & $\mathrm{br}, \mathrm{s}$ & 160.08 & $\mathrm{CH}$ \\
\hline
\end{tabular}

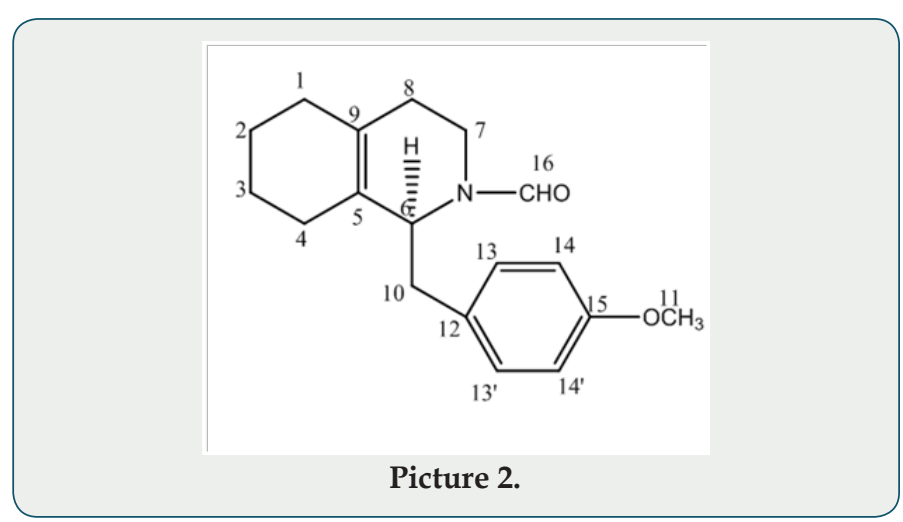

b) Stage-IB: In another flask, charge Ortho phosphoric acid $(\sim 85.0 \% \mathrm{w} / \mathrm{w})$. Charge Toluene and Raise the temperature of the reaction mass. Reflux and maintain over Dean stark apparatus to remove water azeotropically. Cool the reaction mass under nitrogen atmosphere and Charge Phosphorus pentoxide under nitrogen atmosphere. Reaction is highly exothermic. Charge 1-butyl-3-methyl imidazolium acetate. Slowly add N-formyl octa base and Raise the temperature of the reaction mass under nitrogen atmosphere. Stir and maintain the reaction mass at $65-70 \mathrm{oC}$ under nitrogen atmosphere till reaction complies. Concentrate the reaction mass under vacuum to remove toluene. To the concentrated mass, charge ethyl acetate under nitrogen atmosphere and stir. In another flask, charge water, Cool. Charge ethyl acetate reaction mixture reaction mass in to chilled water. Stir, settle and separate the layers. Repeat 
for back extraction. Wash the organic layer with water again and then a wash of $7 \%$ sodium bicarbonate solution is given. Concentrate the organic layer $\mathrm{u} / \mathrm{v}$ till almost no solvent distills. Degas the concentrate $\mathrm{u} / \mathrm{v}$ to remove traces of solvents.

$$
\mathrm{m} / \mathrm{z}(\mathrm{M}+\mathrm{H}+)-286
$$

NMR chemical shift values tabulated below (Table 2) and (Picture 3)

Table 2: s- singlet, m-multiplet, br-broad.

\begin{tabular}{|c|c|c|c|c|c|}
\hline Position & ${ }^{1} \mathbf{H}$ & $d($ ppm) & $\mathrm{J}(\mathrm{Hz})^{1}$ & ${ }^{13} \mathrm{C}$ & DEPT \\
\hline 1 & $2 \mathrm{H}$ & $0.89-1.66$ & $\mathrm{~m}$ & 35.65 & $\mathrm{CH}_{2}$ \\
\hline 2 & $2 \mathrm{H}$ & $0.89-1.66$ & $\mathrm{~m}$ & 21.64 & $\mathrm{CH}_{2}$ \\
\hline 3 & $2 \mathrm{H}$ & $0.89-1.66$ & $\mathrm{~m}$ & $\begin{array}{c}25.65- \\
25.89\end{array}$ & $\mathrm{C}_{\mathrm{H} 2}$ \\
\hline 4 & $2 \mathrm{H}$ & 0.89-1.66 & $\mathrm{m}$ & 30.31 & $\mathrm{CH}_{2}$ \\
\hline 5 & $1 \mathrm{H}$ & $2.63-2.76$ & - & 44.26 & $\mathrm{CH}$ \\
\hline 6 & $1 \mathrm{H}$ & $3.02-3.22$ & $\mathrm{~m}$ & 52.12 & $\mathrm{CH}$ \\
\hline $7 \mathrm{Ha}$ & $1 \mathrm{H}$ & $2.36-2.57$ & $\mathrm{~m}$ & 40.09 & $\mathrm{CH}_{2}$ \\
\hline $7 \mathrm{Hb}$ & $1 \mathrm{H}$ & & & & \\
\hline 8 & $2 \mathrm{H}$ & $0.89-1.66$ & $\mathrm{~m}$ & 34.06 & $\mathrm{CH}_{2}$ \\
\hline 9 & - & - & - & 41.45 & - \\
\hline 10 & $2 \mathrm{H}$ & $2.18-2.3$ & $\mathrm{~m}$ & 31.77 & $\mathrm{CH}_{2}$ \\
\hline 11 & - & - & - & 128.82 & - \\
\hline 12 & - & - & - & 125.22 & - \\
\hline 13 & $1 \mathrm{H}$ & $7.00-7.06$ & $\mathrm{~m}$ & 128.11 & $\mathrm{CH}$ \\
\hline $14,14^{\prime}$ & $2 \mathrm{H}$ & $6.72-6.84$ & $\mathrm{~m}$ & $\begin{array}{c}110.77- \\
111.53\end{array}$ & $\mathrm{CH}$ \\
\hline 15 & - & - & - & $\begin{array}{c}128.87- \\
128.88\end{array}$ & - \\
\hline 16 & $1 \mathrm{H}$ & 7.95-8.11 & $\mathrm{s}$ & 160.54 & $\mathrm{CH}$ \\
\hline 17 & $3 \mathrm{H}$ & 3.73 & $\mathrm{~s}$ & 54.81 & $\mathrm{CH}_{3}$ \\
\hline
\end{tabular}

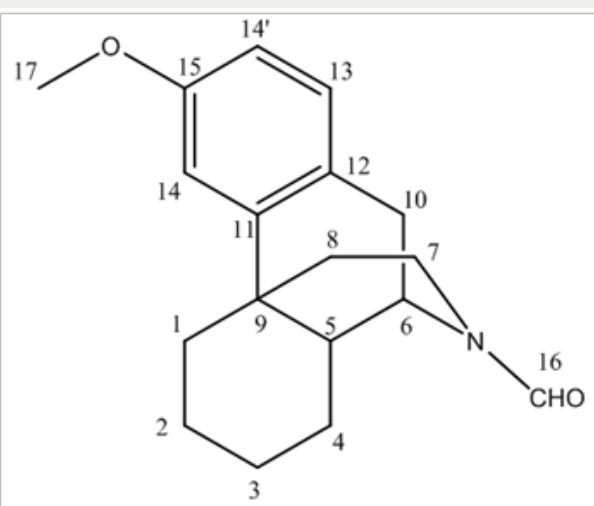

Picture 3.

c) Stage-IC: To the concentrate mass, charge 1-butyl3-methyl imidazolium acetate and methanol under nitrogen atmosphere. Stir and slowly add sodium hydroxide solution PreCooled $\sim 15 \mathrm{oC}$ (Prepare by using $109 \mathrm{~g}$ Sodium hydroxide dissolved in $200 \mathrm{ml}$ Water). Raise the temperature of the reaction mass and

Stir and maintain the reaction mass till reaction complies $(\sim 15$ hours). Concentrate the reaction mass $u / v$. To the concentrate mass, charge toluene under nitrogen atmosphere and water workup is done. The extracted toluene layer was concentrated to give N-Nordextromethorphan (Stage-IC).

$$
\mathrm{m} / \mathrm{z}(\mathrm{M}+\mathrm{H}+)-258
$$

NMR chemical shift values tabulated below (Table 3) and (Picture 4):

\begin{tabular}{|c|c|c|c|c|c|}
\hline Position & ${ }^{1} \mathbf{H}$ & $d(p p m)$ & $\mathrm{J}(\mathrm{Hz})^{1}$ & ${ }^{13} \mathrm{C}$ & DEPT \\
\hline $1 \mathrm{Ha}$ & $1 \mathrm{H}$ & $1.38-1.50$ & \multirow{2}{*}{$\mathrm{m}$} & \multirow{2}{*}{36.50} & \multirow{2}{*}{$\mathrm{CH}_{2}$} \\
\hline $1 \mathrm{Hb}$ & $1 \mathrm{H}$ & $2.27-2.52$ & & & \\
\hline $2 \mathrm{Ha}$ & $1 \mathrm{H}$ & $1.15-1.34$ & \multirow{2}{*}{$\mathrm{m}$} & \multirow{2}{*}{21.82} & \multirow{2}{*}{$\mathrm{CH}_{2}$} \\
\hline $2 \mathrm{Hb}$ & $1 \mathrm{H}$ & $1.38-1.50$ & & & \\
\hline $3 \mathrm{Ha}$ & $1 \mathrm{H}$ & $0.87-0.97$ & \multirow{2}{*}{$\mathrm{m}$} & \multirow{2}{*}{26.46} & \multirow{2}{*}{$\mathrm{CH}_{2}$} \\
\hline $3 \mathrm{Hb}$ & $1 \mathrm{H}$ & $1.15-1.34$ & & & \\
\hline 4 & $2 \mathrm{H}$ & $1.15-1.34$ & $\mathrm{~m}$ & 26.28 & $\mathrm{CH}_{2}$ \\
\hline 5 & $1 \mathrm{H}$ & $1.56-1.67$ & $\mathrm{~m}$ & 45.27 & $\mathrm{CH}_{2}$ \\
\hline 6 & $1 \mathrm{H}$ & $2.84-2.99$ & $\mathrm{~m}$ & 50.18 & $\mathrm{CH}$ \\
\hline 7 & $2 \mathrm{H}$ & $2.27-2.52$ & $\mathrm{~m}$ & 42.39 & $\mathrm{CH}_{2}$ \\
\hline $8 \mathrm{Ha}$ & $1 \mathrm{H}$ & $1.15-1.34$ & $\mathrm{~m}$ & 38.56 & $\mathrm{CH}_{2}$ \\
\hline $8 \mathrm{Hb}$ & $1 \mathrm{H}$ & $1.56-1.67$ & & & \\
\hline 9 & - & - & - & 37.92 & - \\
\hline $10 \mathrm{Ha}$ & $1 \mathrm{H}$ & 2.63 & d (17.4) & 33.05 & $\mathrm{CH} 2$ \\
\hline $10 \mathrm{Hb}$ & $1 \mathrm{H}$ & 2.84-2.99 & $\mathrm{m}$ & & \\
\hline 11 & - & - & - & 141.28 & - \\
\hline 12 & - & - & - & 128.85 & - \\
\hline 13 & $1 \mathrm{H}$ & 7.01 & $\mathrm{~d}(8.4)$ & 128.27 & $\mathrm{CH}$ \\
\hline 14 & $1 \mathrm{H}$ & $6.67-6.75$ & $\mathrm{~m}$ & 110.77 & $\mathrm{CH}$ \\
\hline 15 & - & - & - & 157.70 & - \\
\hline 16 & $1 \mathrm{H}$ & $6.67-6.75$ & $\mathrm{~m}$ & 110.58 & - \\
\hline 17 & $3 \mathrm{H}$ & 3.70 & $\mathrm{~s}$ & 54.77 & $\mathrm{CH}_{3}$ \\
\hline $\mathrm{NH}$ & $1 \mathrm{H}$ & $2.27-2.52$ & br & - & - \\
\hline
\end{tabular}

Table 3: s- Singlet, m-multiplet, br-broad.

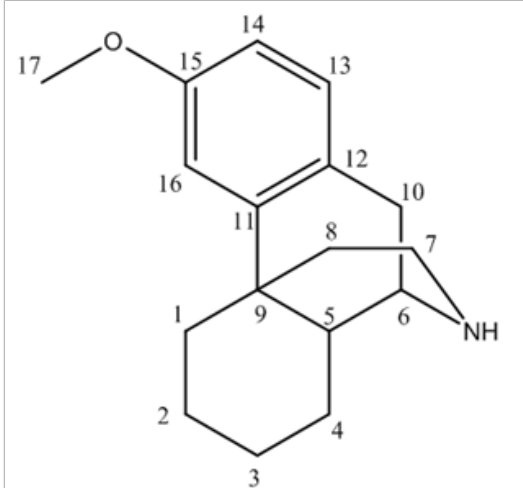

Picture 4. 
d) Stage-ID: To the mixture of1-butyl-3-methyl imidazolium acetate and N-Nordextromethorphan (Stage-IC), slowly add Formic acid solution (Prepare by using 32.1g Formic acid diluted with $5.7 \mathrm{ml}$ water). Charge Formaldehyde solution. Raise the temperature of the reaction mass and Stir and maintain the reaction mass till reaction complies ( $\sim 2$ hours). After the reaction is complete, Charge water and cool the reaction mass if required and then slowly add sodium hydroxide solution Pre-cool ( $<15 \mathrm{oC}$ ) (Prepared by using 28.0g Sodium hydroxide dissolved in $140 \mathrm{ml}$ water), extracted the product into toluene, again charge water, cool, and slowly add Hydrobromic acid. Raise the temperature of the reaction mass to 70-80 oC and Stir and maintain to get clear solution. The organic and aqueous layers separated. Cool the Aqueous layer under stirring to get precipitate and further cooled to 3-6 oC and wash with pre-chilled water. Dry the solid under vacuum, to get Dextromethorphan hydro bromide.

$$
\mathrm{m} / \mathrm{z}(\mathrm{M}+\mathrm{H}+)-272
$$

NMR chemical shift values tabulated below (Table 4) and (Picture 5):

Table 4: s- Singlet, d- doublet, m-multiplet, br-broad.

\begin{tabular}{|c|c|c|c|c|c|}
\hline Position & ${ }^{1} \mathbf{H}$ & ?(ppm) & $\mathrm{J}(\mathrm{Hz})^{1}$ & ${ }^{13} \mathrm{C}$ & DEPT \\
\hline $1 \mathrm{Ha}$ & $1 \mathrm{H}$ & $1.43-1.64$ & \multirow{2}{*}{$\mathrm{m}$} & \multirow{2}{*}{38.51} & \multirow{2}{*}{$\mathrm{CH}_{2}$} \\
\hline $1 \mathrm{Hb}$ & $1 \mathrm{H}$ & $2.44-2.50$ & & & \\
\hline $2 \mathrm{Ha}$ & $1 \mathrm{H}$ & $1.24-1.37$ & \multirow{2}{*}{$\mathrm{m}$} & \multirow{2}{*}{21.38} & \multirow{2}{*}{$\mathrm{CH}_{2}$} \\
\hline $2 \mathrm{Hb}$ & $1 \mathrm{H}$ & $1.43-1.64$ & & & \\
\hline $3 \mathrm{Ha}$ & $1 \mathrm{H}$ & $1.43-1.64$ & \multirow{2}{*}{$\mathrm{m}$} & \multirow{2}{*}{22.65} & \multirow{2}{*}{$\mathrm{CH}_{2}$} \\
\hline $3 \mathrm{Hb}$ & $1 \mathrm{H}$ & 1.11-1.19 & & & \\
\hline $4 \mathrm{Ha}$ & $1 \mathrm{H}$ & $1.42-1.64$ & \multirow{2}{*}{$\mathrm{m}$} & \multirow{2}{*}{25.30} & \multirow{2}{*}{$\mathrm{CH}_{2}$} \\
\hline $4 \mathrm{Hb}$ & $1 \mathrm{H}$ & $1.77-1.88$ & & & \\
\hline 5 & $1 \mathrm{H}$ & $1.77-1.88$ & $\mathrm{~m}$ & 41.40 & $\mathrm{CH}$ \\
\hline 6 & $1 \mathrm{H}$ & 3.62 & $\mathrm{~m}$ & 58.82 & $\mathrm{CH}$ \\
\hline $7 \mathrm{Ha}$ & $1 \mathrm{H}$ & 2.44 & $\mathrm{~s}$ & \multirow{2}{*}{46.95} & \multirow{2}{*}{$\mathrm{CH}_{2}$} \\
\hline $7 \mathrm{Hb}$ & $1 \mathrm{H}$ & $3.11-3.20$ & $\mathrm{~m}$ & & \\
\hline $8 \mathrm{Ha}$ & $1 \mathrm{H}$ & $1.43-1.64$ & \multirow{2}{*}{$\mathrm{m}$} & \multirow{2}{*}{34.72} & \multirow{2}{*}{$\mathrm{CH}_{2}$} \\
\hline $8 \mathrm{Hb}$ & $1 \mathrm{H}$ & $2.01-2.05$ & & & \\
\hline 9 & - & - & - & 35.37 & - \\
\hline $10 \mathrm{Ha}$ & $1 \mathrm{H}$ & $2.93-3.05$ & \multirow{2}{*}{$\mathrm{m}$} & \multirow{2}{*}{25.18} & \multirow{2}{*}{$\mathrm{CH}_{2}$} \\
\hline $10 \mathrm{Hb}$ & $1 \mathrm{H}$ & $3.11-3.20$ & & & \\
\hline 11 & - & - & - & 138.63 & - \\
\hline 12 & - & - & - & 129.27 & - \\
\hline 13 & $1 \mathrm{H}$ & 7.14 & $\mathrm{~d}(9.3)$ & 125.88 & $\mathrm{CH}$ \\
\hline $14,14^{\prime}$ & $2 \mathrm{H}$ & $6.81-6.84$ & $\mathrm{~m}$ & $\begin{array}{l}110.55 \\
112.07\end{array}$ & $\mathrm{CH}$ \\
\hline 15 & - & - & - & 158.44 & - \\
\hline 16 & $3 \mathrm{H}$ & 2.81 & $\mathrm{~s}$ & 40.06 & $\mathrm{CH}_{3}$ \\
\hline 17 & $3 \mathrm{H}$ & 3.73 & $\mathrm{~s}$ & 55.04 & $\mathrm{CH}_{3}$ \\
\hline 18 & $1 \mathrm{H}$ & 9.78 & $\mathrm{br}$ & - & - \\
\hline
\end{tabular}

a) Volatile nature of solvents.

b) Storage and handling risks.

c) Usage requirements in large scale.

Apart from their handling risks to human beings, they also cause significant saturation in chemical pollution levels in the environment; there has been constant research going-on in academic field as well as industries to find their suitable alternative [6].

Ionic liquids are one such alternative that has been found useful to substitute the commonly used bench solvents. Other than their obvious "solvent" property that have been discussed in various publications [7-10], they have also been found to catalyze certain type of reactions in which they participate [11-13]. Moreover, their complete recovery from the reaction is an easy job when juxtaposed with their volatile solvent counterparts. For this reason, an ionic liquid can be re-cycled for multiple batches of reactions.

Another unique property of ionic liquids is that they can be "tailor-made" to suit specific reaction types by playing around with the cation and anion part of them. They are called as "task-specific ionic liquids". These tailored [14] and specially synthesized ionic liquids have more scope of their application in a chemical reaction than just acting as a green solvent.

\section{Conclusion}

A simple, efficient, eco-friendly synthetic route is developed involving the single-step synthesis of Dextromethorphan Hydrobromide that is high on convenience and also a cost-effective 
procedure. This process is best suitable for the preparation of Dextromethorphan Hydrobromide and is scalable in plant. This synthetic route using an ionic liquid adapts a cleaner chemistry that assures both risk-free handling and reduced environmental pollution, when scaled-up.

\section{Acknowledgement}

Our group would like to thank the Department of Scientific and Industrial Research India, Dr. Hari Babu (COO Mylan), Sanjeev Sethi (Chief Scientific Officer Mylan Inc ); Dr Abhijit Deshmukh (Head of Global OSD Scientific Affairs); Dr Yasir Rawjee \{Head-Global API (Active Pharmaceutical Ingredients)\}, Dr Sureshbabu Jayachandra (Head of Chemical Research) Mr Manoj Pananchukunnath (Head of Global Injectables Scientific Affairs, Product Development) Dr. Suryanarayana Mulukutla (Head Analytical Dept MLL API R \& D) as well as analytical development team of Mylan Laboratories Limited for their encouragement and support. We would also like to thank Dr Narahari Ambati (AGC- India IP) \& his Intellectual property team for their support.

\section{References}

1. Reference Tables: Description and Solubility-D.
2. Schwartz, Anna R, Pizon, Anthony F, Brooks, et al. (2008) Dextromethorphan-induced serotonin syndrome. Clinical Toxicology 46(8): 771-773.

3. Shin E, Nah S, Chae J (2007) Neurochemistry International 50(6): 791799.

4. Shin, Eun Jo, (2005) British Journal of Pharmacology 144(7): 908-918.

5. (1998) Eur J Org chem 2101-2108.

6. Wassercheid P, Welton T (2008) Ionic liquids in synthesis, Wiley-VCH ( $2^{\text {nd }}$ edn.), New York, USA.

7. Song CE (2004) Chemical communications 9: 1033-1043.

8. Xiao Y, Malhotra SV (2004) Tetrahedron Letters 45(45): 8339-8342.

9. Handy ST, (2006) Journal of organic chemistry 71(12): 4659-4662.

10. Anjaiah S (2004) Journal of molecular catalysis: Chemical 214(1): 103106.

11. Welton T (2004) Coordination chemistry reviews 248: 2459-2477.

12. Chakraborti AK, Roy SR (2009) Journal of the American chemical society 131: 6902-6903.

13. Zhoa D (2002) Catalysis today 74: 157-189.

14. Zhen L (2012) Scientia sinica chemical 4: 502-524.

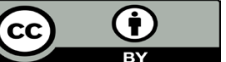

This work is licensed under Creative Commons Attribution 4.0 License

To Submit Your Article Click Here:

Submit Article

DOI: 10.32474/AOICS.2018.03.000156

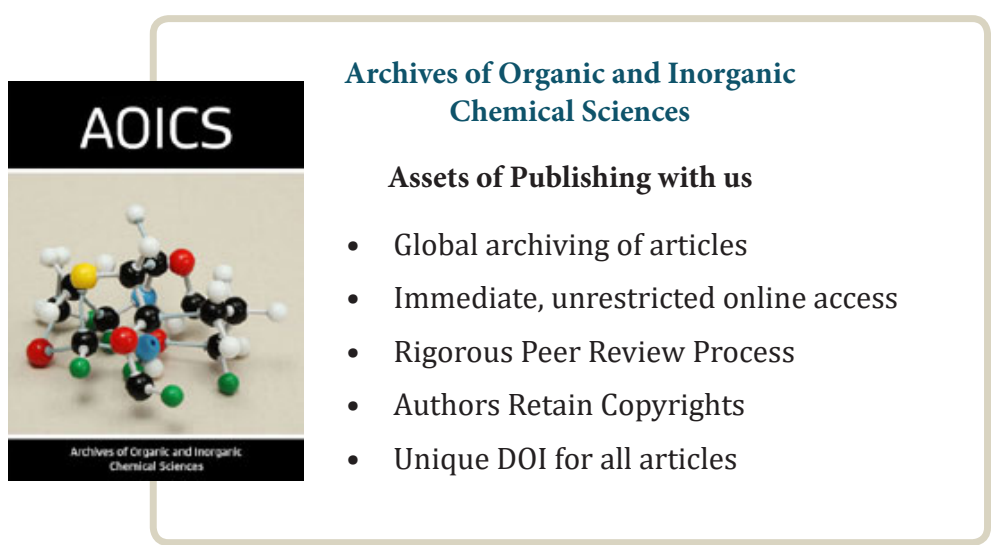

